\title{
Do emergency tests help in the management of acute medical admissions?
}

\author{
GERALD SANDLER
}

\begin{abstract}
A two year combined retrospective and prospective study of 555 acute medical admissions to a district general hospital was carried out to assess the value of emergency biochemical, haematological, radiological, and electrocardiographic tests in diagnosis and treatment. For the study the tests were considered helpful only if they disclosed an abnormality and resulted in a definite diagnosis or change of treatment which would not have been possible from the history and examination alone.

A total of 2372 emergency tests were carried out in the 555 patients who presented with 579 acute medical problems. Only $403(17 \%)$ of the test results were abnormal and, of these, only one third helped in treatment and less than one third helped in diagnosis. The most useful diagnostic tests were serum amylase activity in abdominal pain, the electrocardiogram in chest pain, the chest radiograph in respiratory problems, and cerebrospinal fluid analysis in suspected meningitis or subarachnoid haemorrhage. The most useful tests in treatment were blood sugar value in diabetes, $\mathrm{PCO}_{2}$ in obstructive airways disease, and haemoglobin concentration in gastrointestinal haemorrhage. Of the tests requested by far the most often-blood urea and serum electrolyte concentrations-only $7 \%$ gave abnormal results and were rarely of any help in either diagnosis or treatment.

Analysis of the reasons for the uncritical use of emergency tests by house officers suggested that better undergraduate training, regular audit by senior members of medical units, abolition of routine investigational procedures, and more selective laboratory reports would help to build up the house officer's confidence in his own skills of history taking and physical examination without recourse to indiscriminate use of laboratory and other investigations.
\end{abstract}

Department of Medicine, District General Hospital, Barnsley

GERALD SANDLER, MD, FRCP, consultant physician
In this study the usual emergency tests were considered to have little to offer in aiding diagnosis and treatment. Nevertheless, the results suggested that a normal initial electrocardiogram in patients with chest pain and a normal initial chest radiograph in patients with respiratory infection may be useful in allowing earlier discharge from hospital.

The yearly cost of those out of hours tests that were of no help in diagnosis or treatment was $\$ 4263$. If this pattern is reflected in all 2500 National Health Service hospitals the annual expenditure would range from $£ 101 / 2 \mathrm{~m}$ if a single medical unit were concerned to roughly $£ 42 \frac{1}{2} \mathrm{~m}$ if four medical units contributed per hospital.

\section{Introduction}

With the advances in laboratory testing and the advent of the multichannel analyser the use of these tests is increasing in hospital practice, even though clinical experience often shows them to be of limited value in the management of patients. ${ }^{1-3}$ Apart from devaluing the basic skills of history taking and clinical examinations, the indiscriminate use of such tests imposes an extra heavy financial burden on the National Health Service, and this is made even heavier by requests for emergency tests outside normal working hours, when "on call" rates have to be paid.

I have examined the value of some standard biochemical and other tests in the emergency management of acute medical patients admitted over two years to a general medical unit with a cardiological bias in a district general hospital.

\section{Patients and methods}

The series comprised all 555 patients admitted for acute medical conditions and for whom emergency tests were done. A total of 299 patients were studied retrospectively and 256 prospectively. The male to female ratio was 1.8:1.

The retrospective survey covered one year and the prospective survey one year. The purpose of the retrospective study was to balance the influence of 
any bias in house officers choosing to do emergency tests in the prospective part of the study, when they knew that their use of these tests would be open to scrutiny.

The tests were carried out entirely at the discretion of the preregistration house officers who admitted the patient; the registrar did not help in these decisions. During the two year study four pairs of house officers participated, one for the men's ward and one for the women's ward, interchanging half way through each six months' appointment. I assessed the value of each test retrospectively and considered a test helpful in either diagnosis or treatment only when the result was abnormal and led either to $(a)$ a definite diagnosis not suspected from the history and examination alone or $(b)$ a change in treatment which would not have been prescribed in the absence of the test result.

For this study a negative test result which excluded other possible diagnoses was not designated as helpful (this is discussed in more detail below).

\section{Results}

Table I gives a systematic breakdown of the clinical problems studied; some patients were admitted with more than one acute medical problem. The miscellaneous group was composed mostly of drug overdoses $(69 \%)$ but also included leg vein thrombosis, anaemia, alcoholism, hypothermia, pyrexia of unknown origin, rashes, and malignancy. Table II lists the tests assessed: they included the standard biochemical tests widely used in hospital practice; haematological tests such as blood count and bleeding tests; simple $x$ ray examination of chest, abdomen, and skull; and electrocardiograms. The average number of tests per patient was 3.9 in the prospective study and 4.5 in the retrospective study.

\section{INCIDENCE OF ABNORMAL. TEST RESULTS}

Out of a total of 2372 tests done for 579 clinical problems, only 403 (17\%) showed an abnormality (table III). The highest incidence was in diabetic patients, but even then only one in four tests gave an abnormal result, that test being almost exclusively the blood sugar value. Results in patients with renal problems referred to only eight cases, so that any inference from the relatively high incidence of abnormality would be unreliable. In the remaining systems the incidence of abnormal results was low, ranging from $20 \%$ in respiratory problems to only $9 \%$ in neurological conditions.

Table IV shows the incidence of abnormal results in the individual tests. The most frequent abnormalities were in drug concentrations in patients with self poisoning, haemoglobin concentrations in patients admitted for gastrointestinal bleeding, and serum amylase activities in patients with

TABLE I-Systematic distribution of clinical problems among the 555 patients

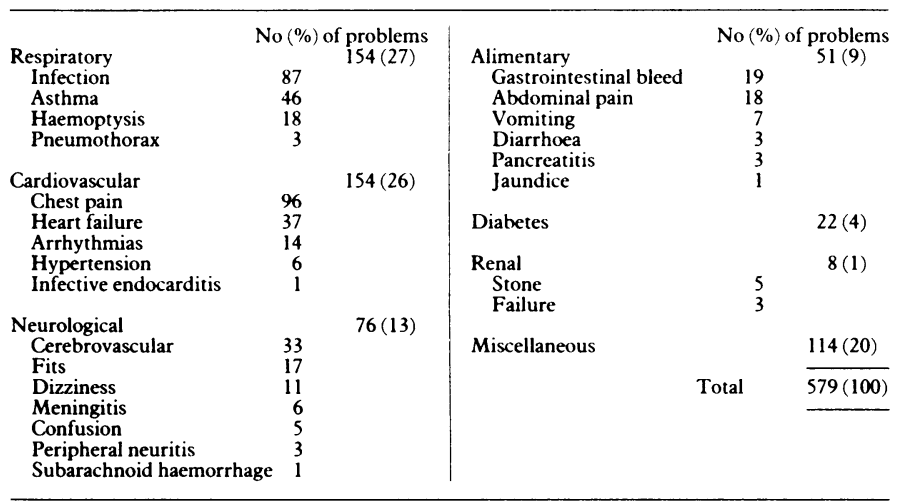

TABLE II-Investigations assessed in study

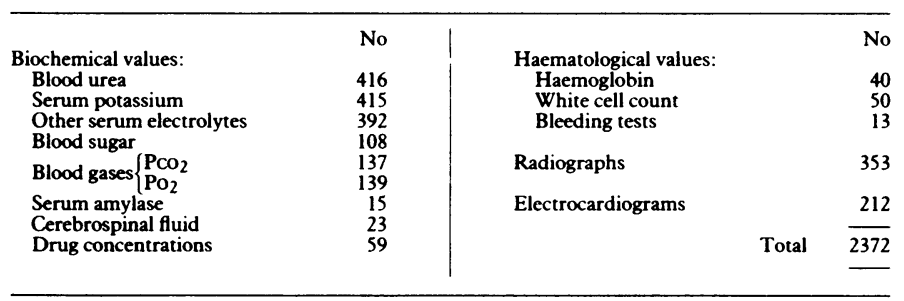

TABLE III-Incidence of abnormal test results and relation to various systems

\begin{tabular}{lccc}
\hline Systems affected & $\begin{array}{c}\text { No of } \\
\text { problems }\end{array}$ & $\begin{array}{c}\text { No of } \\
\text { tests done }\end{array}$ & $\begin{array}{c}\text { \% of } \\
\text { test results } \\
\text { abnormal }\end{array}$ \\
\hline $\begin{array}{l}\text { Diabetes } \\
\text { Renal }\end{array}$ & 22 & 120 & 33 \\
Respiratory & 8 & 26 & 27 \\
Alimentary & 154 & 625 & 20 \\
Miscellaneous & 52 & 240 & 17 \\
Cardiovascular & 114 & 339 & 16 \\
Neurological & 153 & 682 & 14 \\
\hline Total & 76 & 340 & 9 \\
\hline
\end{tabular}

TABLE IV-Incidence of abnormal results in various tests

\begin{tabular}{lcc}
\hline Test & No done & $\begin{array}{c}\% \text { of } \\
\text { results } \\
\text { abnormal }\end{array}$ \\
\hline Drug concentration & 59 & 58 \\
Haemoglobin & 40 & 45 \\
Serum amylase & 15 & 33 \\
Electrocardiograms & 212 & 30 \\
Po2 & 139 & 30 \\
Radiographs & 353 & 29 \\
Blood sugar & 108 & 26 \\
White cell count & 50 & 22 \\
Cerebrospinal fluid & 23 & 22 \\
Pco 2 & 137 & 12 \\
Bleeding tests & 13 & 7 \\
Blood urea & 416 & 6 \\
Serum potassium & 415 & 4 \\
Other serum electrolytes & 392 & 17 \\
\hline Total & 2372 & \\
\hline
\end{tabular}

suspected pancreatitis; of all the other tests, fewer than one third yielded an abnormality, and it is noteworthy that in the tests used most often by far-blood urea and serum electrolyte concentrations - the incidence of an abnormal result was only $4-7 \%$.

Figure 1 shows the tests most likely to give an abnormal result in relation to the various systems affected; tests are included only if at least one third of the results were abnormal. The highest incidence of abnormality was, as expected, in blood sugar measurements in diabetic patients $(91 \%)$, followed by drug concentrations in patients with overdoses $(58 \%)$ and $\mathrm{Po}_{2}$ in patients with heart failure $(57 \%)$.

\section{VALUE OF TESTS}

Of the 403 abnormal test results, fewer than one third helped in diagnosis and one third helped in treatment (table V).

Figure 2 shows the value of the abnormal test results related to the

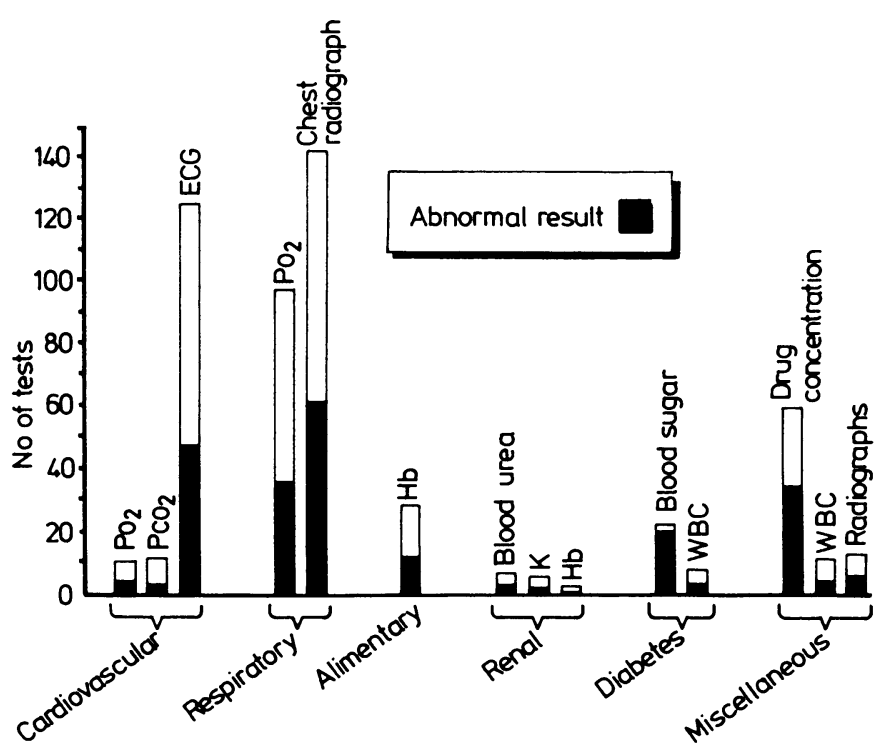

FIG 1-Tests most often giving abnormal results related to system affected. 
TABLE V-Overall value of tests in diagnosis and treatmen

\begin{tabular}{lr|ll}
\hline $\begin{array}{l}\text { No of patients } \\
\text { No of problems }\end{array}$ & 555 & No (\%) of test results abnormal & $403(17)$ \\
No of tests done & 579 & No (\%) helped diagnosis & $101(25)$ \\
& 2372 & No (\%) helped treatment & $138(34)$ \\
\hline
\end{tabular}

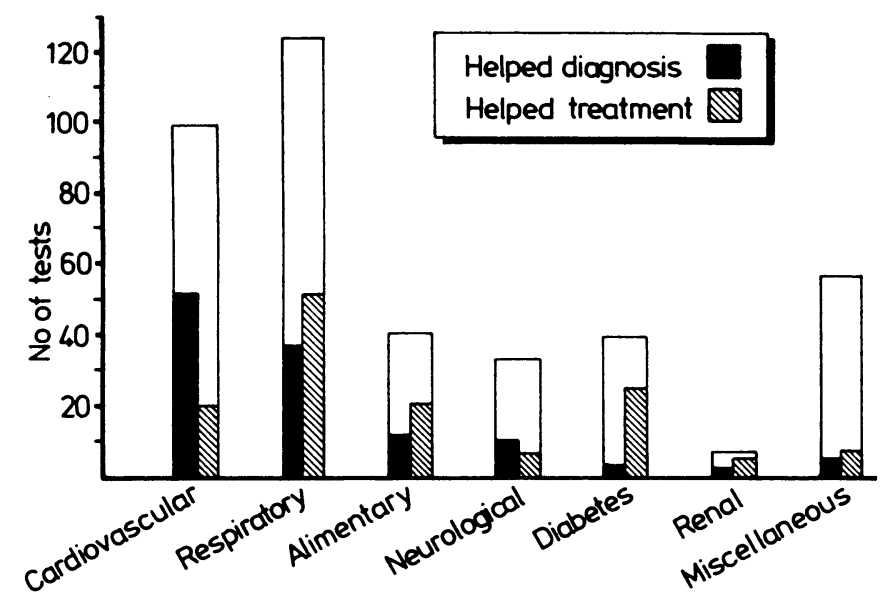

FIG 2-Value of abnormal test results related to individual systems.

TABLE VI-Value of individual tests in diagnosis and treatmen

\begin{tabular}{|c|c|c|c|c|}
\hline \multirow[b]{2}{*}{ Test } & \multirow{2}{*}{$\begin{array}{c}\text { Total No } \\
\text { of tests } \\
\text { done }\end{array}$} & \multicolumn{3}{|c|}{ Abnormal test results } \\
\hline & & No & $\begin{array}{l}\% \text { helped } \\
\text { diagnosis }\end{array}$ & $\begin{array}{l}\text { \% helped } \\
\text { treatmen }\end{array}$ \\
\hline \multicolumn{5}{|l|}{ Biochemical: } \\
\hline Blood urea & 416 & 30 & 20 & 40 \\
\hline Serum potassium & 415 & 26 & 4 & 81 \\
\hline Other serum electrolytes & 392 & 16 & 25 & 44 \\
\hline Blood sugar & 108 & 28 & 18 & 61 \\
\hline Blood gases $\left\{\mathrm{PCO}_{2}\right.$ & 137 & 17 & 6 & 53 \\
\hline Blood gases $\left\{\mathrm{Po}_{2}\right.$ & 139 & 42 & 2 & 48 \\
\hline Serum amylase & 15 & 5 & 80 & $\overline{3}$ \\
\hline Cerebrospinal fluid & 23 & 9 & 40 & 20 \\
\hline Drug concentrations in blood & 59 & 34 & 3 & - \\
\hline \multicolumn{5}{|l|}{ Haematological: } \\
\hline Haemoglobin & 40 & 18 & 5 & 67 \\
\hline White cell count & 50 & 11 & 36 & 36 \\
\hline Bleeding tests & 13 & 1 & - & 20 \\
\hline Radiographs & 353 & 103 & 49 & 27 \\
\hline Electrocardiograms & 212 & 63 & 60 & 11 \\
\hline Total & 2372 & 403 & 29 & 34 \\
\hline
\end{tabular}

individual systems affected. The main diagnostic help was in the cardiovascular system and, less so, in the nervous system; in all other systems the abnormal results were more useful in deciding treatment rather than diagnosis.

Table VI shows the value of the individual tests in diagnosis and treatment. The most useful diagnostic tests were the serum amylase activity in cases of suspected acute pancreatitis and the electrocardiogram in patients with chest pain. Chest radiographs were of diagnostic help in about half the respiratory problems, and cerebrospinal fluid analysis was of some help in diagnosing meningitis and subarachnoid haemorrhage; with all other tests diagnostic help was given by only $2 \%$ to $36 \%$ of the results. By contrast, the abnormal test results were generally more helpful in deciding treatment, and this was especially true of serum potassium and blood sugar concentrations, $\mathrm{PCO}_{2}$, and haemoglobin value, the latter applying mainly to patients admitted for gastrointestinal bleeding.

\section{CHRONOLOGICAL PATTERN OF EMERGENCY TESTS}

Figure 3 shows the number of tests done as a percentage of the number of emergency patients admitted month by month during the six months' house officer appointments. The data for the corresponding months in the four separate six month appointments during the two years of the study are added together to produce a composite six month distribution.

The picture is presented separately for the retrospective and prospective parts of the study so as to delineate any selectivity and bias that may have been introduced into the prospective part by awareness of the house officers that the tests they do will be subsequently analysed and assessed.

In the retrospective part of the study, apart from the fifth month, there was steady progression in the number of patients having tests to a maximum of $69 \%$ in the final month of the appointment. In the prospective part, however, the picture was different: there was progression in the number of patients having tests to the third month, and then a steady fall to an incidence of only $22 \%$ of patients having emergency tests in the last month of the appointment.

To determine whether there was any bias in ordering tests in the prospective part of the study the average number of tests per problem in the different systems affected was compared in the two parts of the study (table VII). The biggest differences related to diabetic and renal problems, but as there were only a few problems of each type ( 22 diabetic, eight renal) any conclusion drawn would be unreliable. With cardiovascular, respiratory, neurological, and miscellaneous problems, however, the number of tests done was consistently lower in the prospective group, which suggests some inhibitory influence on test ordering procedure.

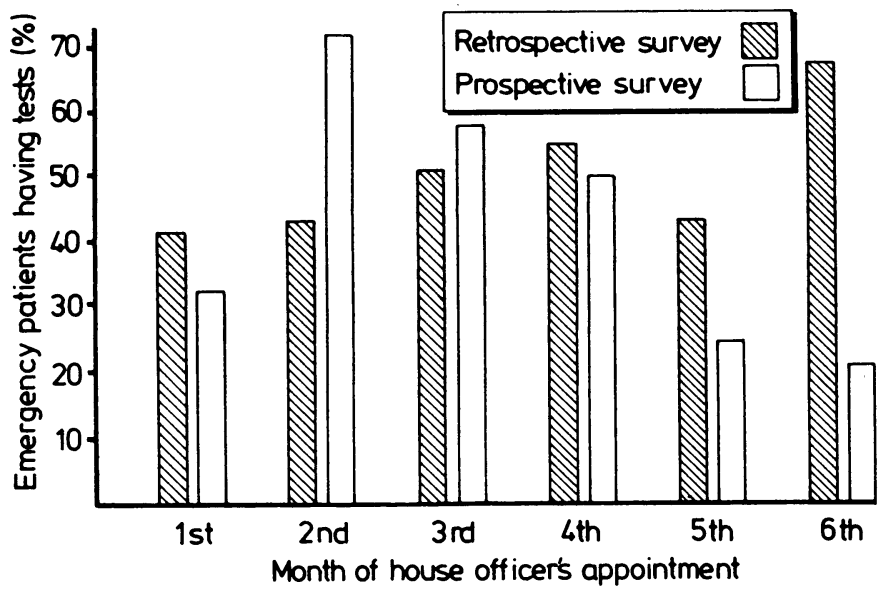

FIG 3-Progressive monthly incidence of tests in emergency admissions during house officer's appointment.

TABLE VII-Comparison of average number of tests per problem between prospective and retrospective studies

\begin{tabular}{lcc}
\hline \multirow{2}{*}{ Systems affected } & \multicolumn{2}{c}{ No of tests/No of problems } \\
\cline { 2 - 3 } & Prospective & Retrospective \\
\hline Cardiovascular & $4 \cdot 1$ & $4 \cdot 6$ \\
Respiratory & $3 \cdot 9$ & $5 \cdot 1$ \\
Neurological & $4 \cdot 6$ & $5 \cdot 2$ \\
Miscellaneous & $2 \cdot 5$ & $3 \cdot 3$ \\
Alimentary & $4 \cdot 7$ & $3 \cdot 6$ \\
Diabetes & $6 \cdot 4$ & $4 \cdot 5$ \\
Renal & $2 \cdot 8$ & $4 \cdot 5$ \\
\hline \multicolumn{1}{c}{ Total } & 3.9 & \\
\hline
\end{tabular}

\section{COSTS OF UNHELPFUL TESTS}

Table VIII shows the costs of emergency tests done outside normal working hours which helped in neither diagnosis nor treatment of the patients. The cost per test includes the call out fee for the technician, the cost of the materials used in the test, and milage expenses based on an average of the miles travelled by the technicians on the rota. The call out fee for laboratory technicians is based on a standard rate, but radiographers are paid a weighted average according to the numbers on the rota. The call out fee for a technician is $£ 7.97$ for all grades and covers a two hour period irrespective of the number of tests carried out. If the time required for the tests exceeds two hours then the technician is entitled to claim a second call out fee.

The total cost of these unhelpful tests over the one year prospective study was $£ 4263$.

There are roughly 2500 hospitals in the National Health Service, most of which are district general hospitals similar to Barnsley in the type of service offered. If the same pattern of doing tests is reflected in all these hospitals the total amount of money wasted yearly on out of hours tests in emergency medical admissions is roughly $£ 421 / 2 \mathrm{~m}$. This figure is based on the activity of one medical unit per hospital; since most general hospitals have several 
medical units (there are four in Barnsley) the figure may be as high as $£ 421 / 2 \mathrm{~m}$ a year if the national average of medical units per hospital is similar to that of Barnsley.

\begin{tabular}{|c|c|c|c|}
\hline Test & $\begin{array}{c}\text { No of } \\
\text { unhelpful tests }\end{array}$ & $\begin{array}{l}\text { Cost per } \\
\text { test }(£)\end{array}$ & $\begin{array}{c}\text { Total } \\
\text { cost }(\mathscr{\varepsilon})\end{array}$ \\
\hline $\begin{array}{l}\text { Blood urea and electrolytes } \\
\text { Blood sugar } \\
\text { Blood gases } \\
\text { Serum amylase } \\
\text { Cerebrospinal fluid } \\
\text { Drug concentration } \\
\text { Blood count } \\
\text { Radiographs } \\
\text { Bleeding tests }\end{array}$ & $\begin{array}{r}116 \\
32 \\
44 \\
5 \\
11 \\
21 \\
57 \\
97 \\
7\end{array}$ & $\begin{array}{r}12 \cdot 16 \\
11 \cdot 98 \\
11.97 \\
12 \cdot 57 \\
12 \cdot 00 \\
14.97 \\
12 \cdot 07 \\
6.83 \\
12.05\end{array}$ & $\begin{array}{r}1410 \\
383 \\
527 \\
63 \\
132 \\
314 \\
688 \\
662 \\
84\end{array}$ \\
\hline Total & 390 & & 4263 \\
\hline
\end{tabular}

\section{Discussion}

This study shows clearly the limited value of emergency tests in the diagnosis and treatment of acute medical admissions to the Barnsley District General Hospital. Out of 2372 tests carried out in 555 patients, only 403 (17\%) showed anything abnormal and, of these, I consider that only about one third were of value in treatment and less than one third were of help in diagnosis.

The immediate question which arises from these data is why the house officers carried out so many useless tests in dealing with their patients. Possible reasons include $(a)$ inexperience and lack of confidence, $(b)$ poor undergraduate training, $(c)$ because the consultant expects it, $(d)$ to detect an associated important but clinically unsuspected condition, and $(e)$ easy availability of the tests.

\section{INEXPERIENCE AND LACK OF CONFIDENCE}

Newly qualified house officers are the ones usually responsible for ordering emergency tests. Their lack of confidence in their diagnostic abilities is due to lack of experience, and as a result they rely more heavily on the tests to help them.

This lack of confidence should be remedied by experience but, more important, by adequate supervision and audit of their performance by a more senior member of the medical unit. Discussion with a senior house officer or, better, a registrar before doing emergency tests would be helpful but periodic consultant assessment of the value of tests carried out by all junior staff would be the most fruitful approach. The problem oriented approach to medical records ${ }^{4}$ has a very significant contribution to make to self audit and improving clinical performance.

In the retrospective study the house officers did not appear to have benefited from their experience in post and so there was no reduction in the number of tests requested; in fact, these increased with time (fig 3). In the prospective study, however, where the house officers knew that their use of emergency tests would be scrutinised, the progressive decrease in tests done during the latter months of the appointment suggested that they had been more critical in their own appraisal of the value of the tests and had accordingly reduced test requirements.

\section{UNDERGRADUATE TRAINING}

Training of medical students still places too much emphasis on the investigational approach in dealing with disease and not enough on the importance and value of the basic skill of history taking and clinical examination. Students, as well as postgraduates, should be trained primarily to take a good clinical history and to draw diagnostic conclusions from this before starting the examination, the purpose of which should be to confirm, amplify, or refute the diagnosis suggested by the history. It is only after this process has been adequately carried out that investigations should be con- sidered, and then only to provide an answer which cannot be obtained from the history and examination alone.

The value of this approach has been well established in two clinical studies in medical outpatients. ${ }^{56}$

\section{CONSULTANT'S EXPECTATION}

Some medical units establish a pattern of routine investigations in various clinical problems which the house officer is expected to follow blindly.

This uncritical approach merely serves to overemphasise the importance of tests in the management of patients and also undermines the build up of the house officer's confidence in his own ability to diagnose and treat patients based on the clinical skills of history taking and physical examination. Where such patterns of routine investigations have been established, regular review of the relevance and value of the tests by the specialist in charge may lead to a more helpful and discriminatory approach.

\section{DETECTING AN UNSUSPECTED CONDITION}

In this study the emergency tests did not show a single instance where a clinically important but completely unsuspected condition came to light. The results of a medical outpatient study ${ }^{5}$ where a similar question was asked in relation to routine tests also showed very little likelihood of picking up unsuspected associated conditions.

\section{EASY AVAILABILITY OF TESTS}

In biochemical investigations the introduction of the autoanalyser has unfortunately led to a more uncritical approach to asking for tests. Computerised laboratory reports usually come back with a variety of unsought, unrequired, and unhelpful measurements. This can only encourage an undesirable non-discriminatory attitude which precludes the necessity to think clearly about the particular problem.

A possible solution is to modify the machine so as to allow selective ordering of single tests, and to combine this with a completely blank request form so that any doctor ordering a test is forced to think clearly and critically about what he really wants.

\section{VALUE OF TESTS IN TREATMENT}

The tests in the study were more helpful in treating the patients than in diagnosing them, though even in that respect only $6 \%$ of all 2372 tests done were of value.

In the cardiovascular system the serum potassium concentration was of value particularly in patients receiving diuretic treatment for heart failure, and to a less extent in myocardial infarction, to warn of the possibility of impending arrhythmias. A normal serum potassium concentration may sometimes be of vaiue in allowing cardioversion of an arrhythmia, but none of the 14 cases of arrhythmia in this study was treated by cardioversion. In the respiratory system the $\mathrm{PCO}_{2}$ was most helpful in patients with obstructive airways disease, especially when the use of positive pressure ventilation was being considered; the $\mathrm{Po}_{2}$ was less helpful in treating these patients, since decisions to give oxygen were usually clinical. In the alimentary system the haemoglobin concentration was of most value, mainly in treating patients admitted for acute gastrointestinal haemorrhage. As expected, the blood sugar concentration was essential in treating diabetics, since it decided in every case what dose of insulin should be given. Measurement of blood urea was the most useful test in renal failure, since it influenced the decision on peritoneal dialysis; in this respect, it was helpful more often than the serum potassium concentration. The most frequent overdose was paracetamol, probably due to its ease of availability; blood concentrations were helpful in deciding the need for specific treatment such as acetylcysteine. 
In an American study of why physicians ordered laboratory tests ${ }^{7}$ two thirds of the physicians circularised considered that the tests had influenced the "diagnosis, therapy, prognosis or understanding of the disease." In that study the tests resulted in a change of diagnosis in $22 \%$ of cases and a change in treatment in $57 \%$, a result similar to that in my study in so far as the tests were also found to be of more value in treatment than in diagnosis.

\section{VALUE OF NORMAL RESULTS}

It may be suggested that this study is unfair in excluding normal test results from being of help in the diagnosis and treatment of emergency patients.

The first difficulty in accepting that normal results help in excluding various possible diagnoses in a particular problem is that it provides a basis for justifying the use of any test in any patient no matter how unlikely the diagnosis suggested. Secondly, assessment of the value of such tests would be very difficult, since the differential diagnosis suggested in a particular problem justifying the use of appropriate tests would vary considerably according to training, experience, and place of work (academic or non-academic) of the doctors concerned, which makes assessment of the value of such tests confusing and unhelpful. Finally-and perhaps the most relevant point in relation to this study-there were few conditions among the patients admitted in which a normal test result would have had a decisive influence in providing an answer to either diagnosis or treatment not possible from the history and examination findings alone (table IX).

Although normal test results would have contributed little to the diagnosis or treatment of the patients (table IX), there was some

TABLE IX-Problems in present study where normal test result might be decisive in influencing diagnosis or treatment

\begin{tabular}{llc}
\hline Normal test result & Clinical problem & No in study \\
\hline & Diagnosis & \\
Serum amylase & Abdominal pain & 18 \\
Cerebrospinal fluid & Meningitis & 7 \\
Chest radiograph & Subarachnoid haemorrhage & 1 \\
Bheumothorax & Treatment & 3 \\
Paracetamol concentration & Diabetes \\
Blood urea & Self poisoning & 22 \\
\hline Total & Renal failure & 20 \\
\hline & & 3 \\
\hline
\end{tabular}

TABLE X-Value of normal test results in relation to earlier discharge of patients

\begin{tabular}{|c|c|c|c|c|}
\hline Problem & Test & & No & $\begin{array}{l}\text { Mean duration of inpatient } \\
\text { stay in days (SE) }\end{array}$ \\
\hline Chest pain & Electrocardiogram & $\left\{\begin{array}{l}\text { Normal } \\
\text { Abnormal }\end{array}\right.$ & $\begin{array}{l}56 \\
26\end{array}$ & $\begin{array}{l}3.52(0.27) \\
6 \cdot 19(0.71)\end{array}$ \\
\hline \multirow{2}{*}{ Respiratory infection } & Chest radiograph & $\left\{\begin{array}{l}\text { Normal } \\
\text { Abnormal }\end{array}\right.$ & $\begin{array}{l}35 \\
31\end{array}$ & $\begin{array}{l}5 \cdot 37(0 \cdot 88)^{\star} \\
7 \cdot 87(1 \cdot 25)\end{array}$ \\
\hline & White cell count & $\left\{\begin{array}{l}\text { Normal } \\
\text { Increased }\end{array}\right.$ & $\begin{array}{l}18 \\
12\end{array}$ & $\begin{array}{l}5.67(0.66) \\
5.42(1.16)\end{array}$ \\
\hline Asthma & $\mathrm{PCO}_{2}$ & $\left\{\begin{array}{l}\text { Normal } \\
\text { Increased }\end{array}\right.$ & $\begin{array}{l}22 \\
14\end{array}$ & $\begin{array}{l}3.95(0.84) \\
4.21(0.44)\end{array}$ \\
\hline
\end{tabular}

«Significant difference $(\mathbf{p}<0 \cdot 05)$

relation between the test result and the length of inpatient stay in patients with the most common medical problems (table X). Patients with chest pain had a significantly shorter inpatient stay when their initial electrocardiogram was normal; similarly, those patients admitted with respiratory infections remained in hospital for a significantly shorter time when their initial chest radiograph was normal. On the other hand, a normal white cell count in respiratory infection or normal blood $\mathrm{PCO}_{2}$ in asthma had no significant influence on duration of stay. These findings suggest that it may be possible to discharge patients with chest pain earlier if their initial electrocardiogram was normal, and similarly patients with respiratory infection and a normal chest radiograph on admission.

I thank my house officers Drs Amanda Blackburn, Beverley Cadman, Sewa Singh, and Stewart Dawson for their cooperation in the prospective part of this study. I am also indebted to my registrar, Dr R Bansal, and my senior house officer, Dr D Purohit, for their help with part of the documentation.

\section{References}

1 Krieg AF, Gambino SR, Galen RS. Why are laboratory tests performed? When are they valid? JAMA 1975;233:76-8.

2 Daniels $M$, Schnoeder SA. Variations among physicians on use of laboratory tests. II. Relation to clinical productivity and outcomes of care. Medical Care 1977;15:482-7.

Brod J. The rational basis of diagnosis in internal medicine. $\mathcal{J} R$ Coll Physicians Lond

4 Weed LL. Medical records, medical education and patient care. Chicago, USA: Case Western University Press distributed by Year Book Medical Publishers, 1969.

Sandler G. Cost of unnecessary tests. Br Med $\mathcal{J} 1979 ; 1 i: 21-4$. examination and lan $\mathrm{M}$, Mitchell $\mathrm{JR}$, et al. Relative cont mate BrMed f 1975 ; $1: 486-9$.

Wertman GB, Sostrin SV, Pavlova Z, et al. Why do physicians order laboratory tests? A study of

(Accepted 17 fuly 1984)
What is the treatment for and prognosis of an astrocytoma in the dorsolumbar region of the spinal cord? Is laser treatment of any value?

Only $13 \%$ of spinal cord astrocytomas occur in the dorsolumbar region. Though it is thought that tumours of the spinal cord in the cervical area are associated with increased risk, there is no correlation between the survival time and the anatomical level at which the tumour of the spinal cord is located. The important factor in prognosis is the histological nature of the tumour. Astrocytomas of the spinal cord are divided into four histological grades, grade 1 being the most benign. About $52 \%$ of spinal cord astrocytomas are grade 1 and $23 \%$ are grades 3 and 4 , in contrast to astrocytomas of the brain, where most astrocytomas are grade 3 or $4 .^{\prime}$ These spinal tumours are often associated with intramedullary cysts. ${ }^{1}$ Treatment varies between needle biopsy and extensive tumour removal, with radiotherapy being used irrespective of the surgical procedure. Postoperative irradiation treatment seems to be beneficial. It has been suggested that radiotherapy after extensive tumour removal in children may not be necessary. ${ }^{2}$ The duration of follow up in that study, however, was short. Survival time seems to be closely allied to the histological features of these tumours, patients with grade 1 after surgery and radiotherapy surviving an average of nine years and patients with grades 3 and 4 an average of $12-18$ months. ${ }^{1}$ Some neurosurgeons consider that the use of the laser in operations on these tumours is an advance. It is difficult, however, to envisage how a surgical tool, even a highly advanced one, can alter the histological picture of a tumour. As yet no critically evaluated series of spinal cord tumours treated by laser have been reported.-G NEIL-DWYER, consultant neurosurgeon, London. 1 Slooff JL, Kernohan JW, MacCarty CS. Primary intramedullary tumours of the spinal cord and elum 2 Epstein F, Epstein N. Surgical treatment of spinal cord astrocytomas of childhood. $\mathcal{J}$ Neurosurg
1982;57:685-9.

A 76 year old patient suffers from nightmares that have been aggravated by the death of his wife a few years ago. What is the most suitable treatment?

It is normal to have occasional nightmares, and they are not experiences to be singled out for treatment by themselves. Anxiety dreams (nightmares) become more frequent when daytime anxiety is raised, and this can be one feature of a depressive illness. Depressive illness is common among the elderly, especially after bereavement. Treatment would depend on full psychiatric assessment and should take into account that the most effective antidepressant drugs are also those that can cause urinary retention. Some sedative/hypnotic drugs, including alcohol, taken in the evening can cause more frequent nightmares.-IAN OSWALD, professor of psychiatry, Edinburgh. 